\title{
Toward a better repair for ischemic mitral regurgitation: Thinking outside the ring
}

\author{
Judy Hung, MD, and Christos Mihos, DO
}

\author{
From the Division of Cardiology, Massachusetts General Hospital, Boston, Mass. \\ Disclosures: Authors have nothing to disclose with regard to commercial support. \\ Received for publication June 8, 2017; accepted for publication June 12, 2017; available ahead of print July 12, \\ 2017 \\ Address for reprints: Judy Hung, MD, Blake 256, Massachusetts General Hospital, 55 Fruit St, Boston, MA 02114 \\ (E-mail: jhung@mgh.harvard.edu). \\ J Thorac Cardiovasc Surg 2017;154:1256-7 \\ $0022-5223 / \$ 36.00$ \\ Copyright (c) 2017 by The American Association for Thoracic Surgery \\ http://dx.doi.org/10.1016/j.jtcvs.2017.06.023
}

Restrictive annuloplasty has been a standard surgical therapy for ischemic (functional) mitral regurgitation (IMR), yet the mechanism of IMR is a subvalvular problem with derangement of the papillary muscles apparatus due to ventricular dilation from coronary artery disease or cardiomyopathy (Figure 1).

Obase and colleagues ${ }^{1}$ report a case series of 9 patients who underwent the " $3 \mathrm{R}$ " repair for functional mitral regurgitation (MR) consisting of anterior leaflet augmentation with pericardial patch, papillary muscle suspension, and ring annuloplasty. Compared with historical controls of 11 patients who underwent ring annuloplasty alone, the authors report that the $3 \mathrm{R}$ repair resulted in no recurrence rate of greater-than-mild MR to date, whereas the ring annuloplasty-alone group had a $56 \%$ recurrence rate of greater-than-mild MR at 5 years.

This report by Obase and colleagues ${ }^{1}$ highlights an active area of interest in cardiac surgery-toward a better repair for IMR. The Cardiothoracic Surgical Trials Network (CTSN) trial on severe ischemic mitral regurgitation, ${ }^{2}$ which was a randomized, multicenter trial in which the investigators compared mitral valve replacement versus mitral valve repair

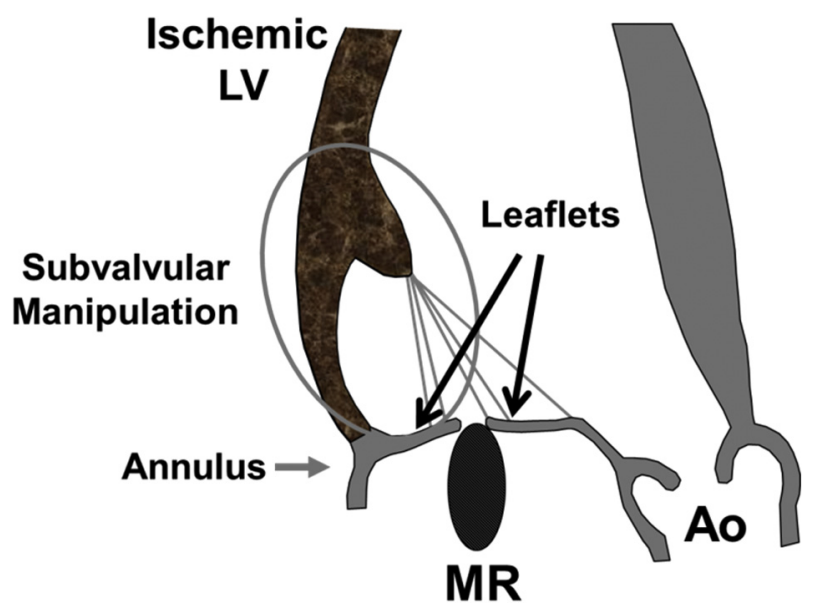

FIGURE 1. Potential therapeutic targets other than annulus for mitral ischemic mitral regurgitation. $L V$, Left ventricle; $M R$, mitral regurgitation; Ao, aorta.

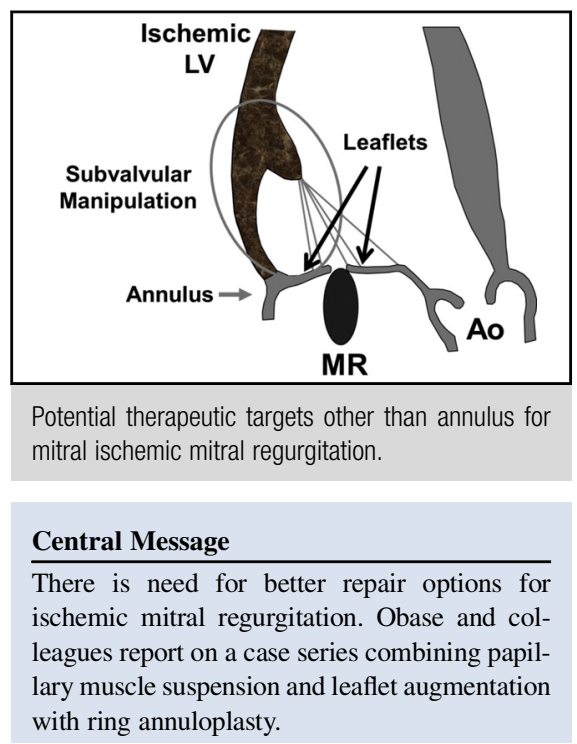

See Article page 1252. with restrictive annuloplasty, showed that there was no difference in the primary outcome of left ventricular end-systolic volume index (LV ESVi) between the 2 groups. Furthermore, the repair group had a significant increase in recurrence rate of moderate or greater IMR at 2 years $(59 \%$ vs $4 \%)$. When the repair group was subcategorized by presence of recurrent moderate or greater MR, patients without recurrent IMR had significantly greater $\mathrm{LV}$ reverse remodeling (LV ESVi = $43 \mathrm{~mL} / \mathrm{m}^{2}$ vs $63 \mathrm{~mL} / \mathrm{m}^{2}$ ), which also was greater than the mitral valve-replacement group ( $\mathrm{LV} \mathrm{ESVi}=61 \mathrm{~mL} / \mathrm{m}^{2}$ ). What this implies is that we need a better, more durable mitral valve repair for IMR than simply restrictive annuloplasty. Kron and colleagues ${ }^{3}$ showed that the mechanism underlying recurrence of IMR in the CTSN severe IMR trial was persistence of leaflet tethering, which was not addressed with ring annuloplasty. The presence of an inferobasal aneurysm or dyskinesis was found to be a predictor of recurrent IMR in this patient population.

Operations that address the subvalvular region or leaflet augmentation to relieve leaflet tethering have been reported previously, mostly in small case series. ${ }^{4,5}$ Small, randomized, single-center studies have been performed for chordal cutting and papillary muscle approximation with encouraging results, demonstrating greater long-term reduction in MR with the addition of subvalvular approaches to ring annuloplasty. 6,7 This case series by Obase and colleagues ${ }^{1}$ combined both leaflet augmentation 
and subvalvular IMR repair. What we don't know is which patients will benefit from ring annuloplasty versus subvalvular manipulation versus leaflet augmentation or a combination. There is a need for larger-scale, multicenter randomized studies to test efficacy of subvalvular and leaflet augmentation approaches to treating IMR. At a minimum, registry data would be highly valuable. Patients with IMR have a poor prognosis. The time is now to "think outside the ring" by continued innovation to provide more and better therapeutic options.

\section{References}

1. Obase K, Matsumaru I, Miura T, Eishi K. Echocardiographic visualization and quantification of mitral complex during mitral repair for severe functional mitral regurgitation. J Thorac Cardiovasc Surg. 2017;154:1252-5.
2. Goldstein D, Moskowitz AJ, Gelijns AC, Ailawadi G, Parides MK, Perrault LP et al. Two-year outcomes of surgical treatment of severe ischemic mitral regurgitation. N Engl J Med. 2016;374:344-53.

3. Kron I, Hung J, Overbey JR, Bouchard D, Gelijns AC, Moskowitz AJ, et al. J Predicting recurrent mitral regurgitation after mitral valve repair for severe ischemic mitral regurgitation. J Thorac Cardiovasc Surg. 2015;149:752-61.

4. Mihos C, Santana O. Can papillary muscle interventions improve mitral valve repair durability for ischemic mitral regurgitation? J Thorac Cardiovasc Surg. 2015;150:427-8.

5. Kincaid EH, Riley RD, Hines MH, Hammon JW, Kon ND. Anterior leaflet augmentation for ischemic mitral regurgitation. Ann Thorac Surg. 2004;78 564-8; discussion 568.

6. Borger M, Murphy PM, Alam A, Fazel S, Maganti M, Armstrong S, et al. Initial results of the chordal-cutting operation for ischemic mitral regurgitation. J Thorac Cardiovasc Surg. 2007;133:1483-92.

7. Nappi F, Lusini M, Spadaccio C, Nenna A, Covino E, Acar C, et al. Papillary muscle approximation versus restrictive annuloplasty alone for severe ischemic mitral regurgitation. J Am Coll Cardiol. 2016;67:2334-46. 